\title{
Imagination, literature, medical ethics and medical practice
}

\author{
Raanan Gillon Imperial College of Science, Technology and Medicine, University of London
}

Without imagination - without an actively cultivated imagination - not only do health care workers themselves suffer, but so too do their patients, argues $\mathrm{Dr}$ Anne Scott in this issue of the journal. ${ }^{12}$ Why? Because only by being able to imagine what it is like to be the other person, the patient, only by being able to enter imaginatively into the world of the patient, is the health care professional able properly to consider the particular situation of the individual patient and the likely implications for that patient in that situation of alternative options. But, argues Dr Scott, a nurse and philosopher who teaches nurses ethics, the moral imagination has to be stimulated, cultivated, educated, nurtured and developed. One valuable way of doing all this is "through the use of the humanities, perhaps particularly the serious reading of literature, especially certain types of novel".

In an age of ever-increasing identification of medicine with science, of increasing appeal to "evidence-based medicine" where the paradigm of "evidence" is the statistically valid result of a well-performed randomised controlled clinical trial, the modern scientific doctor might scornfully riposte that the study of literature as a valid part of medical education (and indeed of contemporary nursing education) is a retrogressive move back to the realm of the "anecdote" or the individual case history, and as such a betrayal of the scientific nature of medicine.

Similarly, and paradoxically, the contemporary moral philosopher, even one involved in medical ethics, may also react with scorn to the proposal that stimulation of the imagination by reading literature can play much of a part in the pursuit of medical ethics. Ethics as a component of philosophy requires development of rigorous powers of reasoning, of argument and counterargument; individual cases as manifested either in real life or in literature may provide the grist for the mill of philosophical reasoning, but their importance for medical ethics is as stimuli for reasoning and argument, as testbeds for moral hypotheses.

Both positions, it will be argued briefly, are based upon false antitheses; neither the scientific component of medicine nor the reasoning and argument of philosophical medical ethics are incompatible with the development of imagination through the reading of literature; rather, both are complemented by it, Nec and it by them.

First, medical science. If it is agreed that the primary function of medical science is to make으 medical practice better, by improving our existingways of helping people - especially, though not only, $\mathbb{\Phi}^{\top}$ sick people - to better health, then the objective of helping individual people, becomes embedded within the very purpose of medical science. Medical science thus has embedded within it a moral purpose, notably $\overrightarrow{0}$ health benefit for people, just as and just because. $v$ medicine itself has embedded within it this moralo purpose. If we then agree that people's decisions about what counts as "help" and "benefit" are at least $\frac{\bar{O}}{\mathrm{O}}$ to some extent subjective, at least to some extent par-® ticular and at least to some extent related to context,,$\stackrel{\mathbb{Q}}{\varrho}$ then the need becomes demonstrable for medical $\vec{F}$ science to ally itself with ways of understanding 3 people, in their particularity and in their context. In? short, the science of medicine must, if it is to optimiseo achievement of its objective of improving the practice of health care, collaborate with the art of medicine, $a_{\Phi}$ central part of which is the understanding of people, especially sick people.

At the heart of understanding people, especiallyo sick people, is experience of being with, listening to, talking with, sick people - in short experience of prac-윽 tising medicine. But such experience is ever-more $>$ limited by the demands of faster "throughput", of the을. mastery and practice of more and more techniques, $N$ and of the ever-increasing demands on the time of both medical scientists and clinicians. But even were 0 there far more time available to talk with our patients, $\mathcal{\omega}$ our understanding of the depth and variety of humañ experience, our ability to share in the experiences ofo others, all can be enriched by good literature - byळ reading novels, stories, plays and poetry.

King Lear is not a play about geriatrics; but our understanding of a particular old man enraging and웅 enraged by two daughters (and their husbands), $\stackrel{?}{\stackrel{?}{\mathscr{Q}}}$ coming at last and too late to understand and appreci-这 ate a third, perhaps equally stubborn, daughter, enlightens our. understanding of so many more old $\mathrm{O}$ men and their children. How much more difficult sucho understanding makes it to write off a cantankerous old man as the "nutty old crumble" in bed three. Sylvia 
Plath will enhance our empathy with, our understanding of, not only this strange and tortured poet herself but also those she observes, describes, evokes so acutely, whether in pregnancy (Three Women), after a suicide attempt (Lady Lazarus), in the chaos of feverish delirium (Fever 103) or in imagining deformities (Thalidomide). Vladimir Nabokov in Lolita makes the paedophile Humbert Humbert real, amusing, sympathetic, as well as sick, callous and dangerous.

Even this brief reminder of some possible contributions to medical education of a randomly chosen triplet of writers should be enough to support and illustrate the claim that literature can help expand the imagination of doctors, nurses and other health carers and help them understand better the people they meet in the course of their work. In so doing, it can help them link the aims of scientific medicine to the range of hopes and fears of the people medicine serves.

Similarly philosophical medical ethics has no need or justification for scorning the use of literature to develop the moral imagination of health care students. Once again it is not a case of either or, but of both. For once again in philosophical medical ethics the general and intellectually rigorous concerns of moral philosophy must be applied to real moral problems of the sort encountered in health care practice. Fundamental to moral analysis of such "cases" is an understanding of their "case histories", the stories of the people who are the "cases" themselves, in all their complexity and particularity and in their contexts. And similarly, too, that understanding, in great part gained through clinical experience, can be enhanced by reading good poems, good novels, by seeing good plays.

But just as individual stories and individual remedies are insufficient for good scientific medicine - they need to be analysed, generalised, hypothesised about and used as the stimuli and bases for research leading to generalisable conclusions in medical science, so too are they insufficient for medical ethics. Instead the particularities of individual stories in their particular contexts need to be brought into "reflective equilibrium" with moral theory; they too need to be analysed, generalised, hypothesised about, and used as the stimuli and bases for research and reflection leading to generalisable conclusions in philosophical medical ethics.

Without such reflective equilibrium, without the limits set by generalisable scientific and ethical theory, individual stories and remedies, especially when understood "imaginatively", are not only insufficient for good medical practice, they can also be harmful. Just as medical science and medical ethics need imaginative understanding of particular stories of particular people if they are not to be at best useless, at worst harmful, so too does imaginative understanding of a particular "case", need the guidance of medical science and medical ethics if it is to lead to good medical practice. Why? Because without such guidance, imaginative interpretation of individual stories, whether by the patient, the health care worker, or the writer, is liable to be wrong, scientifically and/or morally, both in the particular case, and when imaginatively extrapolated to other cases.

People's vivid imaginations may lead them completely astray: think of a twenty-year-old whose pulled intercostal muscle pain leads him to imagine wrongly that he's having a heart attack; of a doctor, who imagines that his patient's tears when discussing a dire prognosis show (a) that the patient would have preferred not to know and (b) that what he perceives to be this patient's preference is relevant to the next patient's preferences.

How much more powerfully and persuasively misguided and misguiding can the writer's imagination be. To return to Lolita, just as Nabokov's novel provides an enlightening and sympathetic account of Humbert Humbert, so too it surely fails to provide a real and sympathetic account of the adolescent Lolita; it surely fails to depict the psychological harm that such a relationship of sexual abuse is likely to inflict upon a child - (a failure unremedied by Nabokov's killing off of the child bride in stillborn labour). Thus while the doctor who uncritically accepts Nabokov's account of the paedophile is likely to be a better forensic psychiatrist for reading the novel, he or she is at risk of being a worse paediatrician. Nabokov's powerful imagination guides medical practice in the case of Humbert Humbert, misguides in the case of Lolita herself. Which is only to show that uncritical acceptance of the offerings of the imagination about particular cases can be harmful for medical practice.

Plato warned of the danger that imagination can lead us away from the truth, and his ideal state banned the tragedian as too liable to lead the populace astray; Hume pointed out that "nothing is more dangerous to reason than flights of the imagination, and nothing has been the occasion of more mistakes among philosophers"; and Kant warned that though imagination is essential for both our perception and our understanding of the world, imagination is a "blind" function of the soul, of whose workings we normally are unaware.

Such warnings are an important antidote to excessive reliance on any one of the triplets we have been considering - medical science, philosophical medical ethics, and the individual's story imaginatively construed. Medical practice requires a mutually supportive alliance of all three. Literature can illuminate our interpretation of our patients' stories; those stories and their interpretation can illuminate both medical science and philosophical medical ethics. Conversely, medical science and philosophical medical ethics can inform and thus illuminate both our interpretation of our patients's stories, and how we ought to respond to them.

\section{References}

1 Scott PA. Imagination in practice. Fournal of Medical Ethics 1997; 23: 45-50.

2 See also the volume devoted to literature and medical ethics: fournal of Medicine and Philosophy 1996; 21,3. 